\section{Evolución del concepto etnia/raza y su impacto en la formulación de políticas para la equidad}

\author{
Cristina Torres-Parodi ${ }^{1}$ \\ y Mónica Bolis ${ }^{1}$
}

En América Latina existen notables desigualdades en relación con el estado de salud y el acceso a los servicios de salud de grupos étnicos/raciales en comparación con el resto de la población. Esta situación es frecuente en países con diferentes niveles de desarrollo, lo que indica que no es solo consecuencia del nivel económico del país, sino también de las estructuras político-sociales prevalecientes. Uno de los requisitos fundamentales para alcanzar la equidad es reconocer las diferencias que se derivan de la propia identidad de los individuos. Es por ello que este estudio pretende, desde el entendimiento de la evolución del concepto etnia/raza, contribuir a la formulación de políticas y programas de salud con un enfoque de equidad y facilitar la participación de los grupos étnicos/raciales en este proceso.

Para este estudio se analizó la evolución del concepto etnia/raza en los tratados, convenios y declaraciones internacionales de derechos humanos y en las recomendaciones y declaraciones que sobre el tema han emitido las conferencias mundiales y las cumbres regionales, en el entendido de que estos instrumentos constituyen fundamentos centrales para el desarrollo de políticas dirigidas a combatir la discriminación. Para revisar la evolución del concepto etnia / raza también se tuvieron en cuenta elementos provenientes de la historia de los movimientos sociales y políticos orientados a superar la discriminación y el racismo. El estudio abarcó de 1948 hasta septiembre de 2007, período en el que el tema de los derechos humanos y la superación del racismo, la discriminación y la xenofobia ha estado persistentemente presente en las agendas políticas internacionales acompañando una evolución positiva del concepto etnia/raza. La progresiva actualización de este concepto es relevante, ya que ha permitido incluir en el ámbito de los grupos beneficiarios a los pueblos indígenas que tradicionalmente se autodefinieron como étnicos/raciales y a otros grupos como los afrodescendientes, los migrantes y los pueblos rom (gitanos).

\section{ETNIA/RAZA: DIVERSAS ETAPAS EN EL DESARROLLO CONCEPTUAL}

El esfuerzo internacional sostenido a lo largo de más de cinco décadas ha permitido desarrollar una amplia batería de instrumentos para superar las barreras de la discriminación, el racismo y la xeno- 
fobia. El punto de partida de este proceso fue la Declaración Universal de los Derechos Humanos (1) ${ }^{2}$ y culminó con los mandatos emanados de la Tercera Conferencia Mundial contra el Racismo, la Discriminación Racial, la Xenofobia y las Formas Conexas de Intolerancia realizada en Durban, Sudáfrica, en 2001 (2). El análisis de estos instrumentos permite identificar cuatro etapas, en las que se distingue una evolución positiva del concepto etnia/raza, y revisar cómo este concepto se incorpora a los lineamientos internacionales para promover los derechos humanos de las minorías étnicas/raciales. ${ }^{3}$ Estas etapas coinciden con distintos momentos del desarrollo de las relaciones políticas y sociales entre las instituciones del Estado y las minorías étnicas / raciales y tienen su fundamento en las distintas maneras de enfocar la ciudadanía en general y la de estos grupos en particular.

Si bien el debate sobre la existencia de diferencias de carácter biológico entre los seres humanos aún no se ha agotado ${ }^{4}$, en el Informe de la Reunión de Consulta sobre la Conferencia Mundial contra el Racismo, la Discriminación Racial, la Xenofobia y las Formas Conexas de Intolerancia, celebrada en Bellagio, Italia, del 24 al 28 de enero de 2000, se afirma que "[L]a inmensa mayoría de los expertos en la materia coincide en que, desde el punto de vista científico y antropológico, el concepto de que los seres humanos pueden dividirse y clasificarse definitivamente en distintas 'razas' carece de fundamento. No hay más que una raza: la raza humana" (6). Por ende, la noción de raza no es una entidad biológica y debe entenderse a la luz de la historia y de las relaciones sociales. Esta evolución se refleja en los lineamientos internacionales de la lucha contra la discriminación.

La "etnicidad" se refiere a la identificación de una colectividad humana a partir de antecedentes históricos y un pasado común, así como de una lengua, símbolos y leyendas compartidos. Originalmente, este término se empleaba en el lenguaje

\footnotetext{
2 Existen antecedentes previos, en términos de la igualdad ante la ley y la justicia, en la Declaración de los Derechos del Hombre y del Ciudadano de Francia (1789). Los decretos del 4 y del 11 de agosto de 1789 , también de Francia, suprimieron los derechos feudales. Otro antecedente es la Convención sobre la Esclavitud, de la Sociedad de las Naciones (9 de marzo de 1927), posteriormente modificada por el protocolo aprobado en la Sede de las Naciones Unidas el 7 de diciembre de 1953 y que entró en vigencia el 7 de julio de 1955.

3 El concepto de minoría al cual se alude en este trabajo no se refiere al porcentaje de la población étnica/racial respecto al total de la población de un país, sino a los grupos étnicos con insuficiente nivel de representación política y social.

4 Los avances científicos han puesto de manifiesto que desde el punto de vista genético, cada individuo es único y que esta variación excede a las variaciones que existen entre grupos. No obstante, la producción científica no es todavía categórica en la interpretación de la influencia del contexto sociohistórico en la determinación de esa diversidad y en cómo las diferencias biológicas impactan la dinámica y la construcción social de identidades. Véanse al respecto los trabajos de Gannet (3), Long y Kittles (4) y Mayr (5).
}

corriente para hacer referencia a "naciones", aunque también estuvo asociada con lo "salvaje" o poco desarrollado y se usó como sinónimo de "tribal". Los esfuerzos académicos realizados en las décadas de 1970 y 1980 perfeccionaron la definición de etnicidad y la relacionaron con las diferencias culturales. La identidad étnica de las personas, tanto en el orden individual como colectivo, no es un factor estático o inmutable sino que, por el contrario, "la etnicidad surge y se transforma en el contexto de las relaciones y conflictos sociales" (7). Entender a los seres humanos en el marco de su humanidad compartida permite visualizar más claramente las relaciones de sumisión y de exclusión injustas que se agazapaban en las clasificaciones arbitrarias del orden social. Estos mecanismos de sumisión, que operaban según las diferencias en el fenotipo, tuvieron su origen en el colonialismo y persistieron ocultas bajo el discurso del mestizaje y de categorías tales como "pueblo", "campesinos" o "clase".

\section{Primera etapa: $1948-1970$}

La Declaración Universal de los Derechos $\mathrm{Hu}$ manos marcó el comienzo de un nuevo paradigma al constituirse en un catálogo de derechos reconocidos universalmente como sustento de la justicia y la paz. La Declaración retomó los derechos más clásicos en relación con el derecho a la vida, la libertad, la prohibición de la trata de esclavos, la igualdad ante la ley, la libertad de circulación, el derecho de opinión, a un juicio imparcial, a la libertad de pensamiento, de conciencia y de religión y de reunión. Además, incorporó otros derechos fortalecidos en períodos más recientes, tales como el derecho a la representación política, la libre elección del trabajo, la sindicalización, la inviolabilidad del domicilio, la prohibición de la detención arbitraria y la igualdad de remuneración por una misma tarea.

En su primer considerando, la Declaración utiliza el concepto de familia humana ${ }^{5}$ y en sus artículos sucesivos hace referencia a la raza, el color (aludiendo sin dudas al color de la piel), el sexo, el idioma, la religión, la opinión política o de cualquier otra índole, el origen nacional o social, la posición económica, el nacimiento o cualquier otra condición. Por lo tanto, si bien la Declaración fue precursora en alentar la igualdad, según parece desprenderse de la terminología adoptada, no permitió superar las visiones fragmentadas en términos de la condición humana.

\footnotetext{
5 “Considerando que la libertad, la justicia y la paz en el mundo tienen por base el reconocimiento de la dignidad intrínseca y de los derechos iguales inalienables de todos los miembros de la familia humana".
} 
Aparentemente, la Declaración utilizó los términos raza, origen nacional y religión sin otorgarles la elaboración conceptual necesaria para crear las bases de una igualdad que no fuera meramente de forma, sino que se sustentara en elementos de fondo. En particular, el uso del vocablo "raza" parece indicar que admite la existencia de razas desde el punto de vista biológico y no sociológico, como surgió más tarde en la Reunión de Consulta de Bellagio.

De lo anterior se derivaría que la Declaración Universal de los Derechos Humanos podría haber dado lugar a interpretaciones contraproducentes. $\mathrm{Si}$ bien la Declaración no eludió la existencia de diferencias en términos de sexo, color o religión, la interpretación del mandato en cuanto a la acepción de raza, como categoría de discriminación que había que eliminar, llevó a producir prácticas que atentaban contra la misma igualdad que buscaban, al generar en algunos países una "cultura del silencio" que prefirió no preguntar el origen étnico o racial de las personas para no evidenciar desigualdades. La cultura del silencio se constituyó sobre el entendido de que la "identidad cultural" tiene un carácter reservado y que pertenece a la esfera privada de las personas. Esto llevó a dar igual tratamiento, por ejemplo, a la identidad religiosa o a la orientación sexual, que al origen étnico de las personas, sin tomar en consideración que estas identidades - por tener diferentes manifestaciones - tienen diferentes percepciones e implicaciones y que algunas son más privadas que otras. Muchas veces, como medio para llegar a la igualdad se prefirió "invisibilizar" las diferencias. Esto se nota en particular en la exclusión de la variable raza en la recolección de información estadística y en la formulación de políticas de carácter universalista, que no fueron sensibles a las necesidades específicas de los diferentes grupos.

En América Latina, algunos países como México y Perú fueron precursores en reconocer el peso de las culturas precolombinas en la construcción de la identidad nacional, pero la óptica imperante en esta etapa fue aún la antropológica, entendida más como legado de un pasado heroico que como realidad social presente. La ideología del indigenismo, vehiculizada desde las instituciones del Estado, ${ }^{6}$ tenía la tendencia de analizar a sus beneficiarios como "exóticos" y muchas veces entendían sus acciones como civilizadoras frente a lo "salvaje", pero con un mensaje cultural monolítico y etnocéntrico.

Por otra parte, los procesos de descolonización ocurridos a partir de la segunda mitad del de-

\footnotetext{
6 En la primera mitad del siglo XX, en algunos países de América Latina, como Colombia, México y Perú, se crearon resguardos para los indígenas e institutos para el estudio de su cultura.
}

cenio de 1950 en todo el mundo modificaron las relaciones de poder entre los grupos de diferentes orígenes étnicos. Esta descolonización contribuyó a eliminar las barreras propias de las sociedades coloniales, que se caracterizaban por limitar el acceso igualitario de los individuos a la ciudadanía, y tuvo efectos positivos en la recuperación de identidades culturales, territorios, lenguas y autonomías, con la consiguiente conquista de la participación social y política.

Otra influencia decisiva en este cambio de enfoque sobre el tratamiento de las minorías étnicas/ raciales fue el movimiento para el rescate de los derechos civiles de la población estadounidense de ascendencia africana. El movimiento de los derechos civiles en los Estados Unidos de América luchó contra la segregación a la que estaban sometidos sus ciudadanos de ascendencia africana y produjo una brecha en la cultura del silencio. En este período también se comenzó a distinguir entre la discriminación individual por el origen étnico/racial y la de carácter institucional. El movimiento de los derechos civiles en los Estados Unidos fue el catalizador de la sociedad civil organizada que reclamaba los derechos de las comunidades de descendientes de africanos.

En 1965 se adoptó la Convención Internacional sobre la Eliminación de Todas las Formas de Discriminación Racial (8), la que por primera vez incorporó una definición operativa de discriminación racial como "toda distinción, exclusión, restricción o preferencia basada en motivos de raza, color, linaje $\mathrm{u}$ origen nacional $\mathrm{o}$ étnico que tenga por objeto o por resultado anular o menoscabar el reconocimiento, goce o ejercicio, en condiciones de igualdad, de los derechos humanos y libertades fundamentales en las esferas política, social o cultural, o en cualquier otra esfera de la vida pública" (artículo 1). La Convención incorporó, también por primera vez, una anticipación a las acciones hoy llamadas afirmativas al establecer en su artículo 1.4 que "[L]as medidas especiales adoptadas con el fin exclusivo de asegurar el adecuado progreso de ciertos grupos raciales o étnicos o de ciertas personas que requieran la protección que pueda ser necesaria con objeto de garantizarles, en condiciones de igualdad, el disfrute o ejercicio de los derechos humanos y de las libertades fundamentales no se considerarán como medidas de discriminación racial, siempre que no conduzcan, como consecuencia, al mantenimiento de derechos distintos para los diferentes grupos raciales y que no se mantengan en vigor después de alcanzados los objetivos para los cuales se tomaron".

La Convención garantiza, asimismo, todos los derechos civiles, políticos, económicos, sociales y culturales: trabajo, vivienda, salud pública y asis- 
tencia médica, seguridad social, educación, participación en las actividades culturales y libre acceso a los lugares públicos.

Otro importante instrumento internacional adoptado en este período fue el Pacto Internacional de Derechos Económicos, Sociales y Culturales (9). En su artículo 2.2 se recupera la misma definición de la Declaración Universal de los Derechos Humanos, al referirse a "[L]os Estados Partes en el presente Pacto se comprometen a garantizar el ejercicio de los derechos que en él se enuncian, sin discriminación alguna por motivos de raza, color, sexo, idioma, religión, opinión política o de otra índole, origen nacional o social, posición económica, nacimiento o cualquier otra condición social". Sin embargo, en el artículo 13 agrega un elemento nuevo al hacer un llamamiento a los Estados Partes a reconocer el derecho de toda persona a la educación, con el fin de hacer de ella un instrumento para el desarrollo de la personalidad y la dignidad humanas y el respeto a los derechos humanos y las libertades fundamentales. De esta forma, confiere a la educación la función de "capacitar a todas las personas para participar efectivamente en una sociedad libre, favorecer la comprensión, la tolerancia y la amistad entre todas las naciones y entre todos los grupos raciales, étnicos y religiosos ..."

Si bien el Pacto es novedoso al aportar la tolerancia como regla de convivencia social y en entender que la dignidad humana se construye sobre la base de la educación, omite incorporar entre los componentes de la educación la revalorización de los aspectos culturales de los distintos grupos. Esto puede haber sido el reflejo de procesos de aculturación que prescindieron de los aportes históricos de las culturas de los grupos étnicos/raciales.

En la Región de las Américas, la Organización de Estados Americanos se hizo eco de esta discusión y en 1969 adoptó la Convención Americana sobre Derechos Humanos (10), que en su artículo 1 establece que "los Estados Partes [. . .] se comprometen a respetar los derechos y libertades reconocidos en ella y a garantizar su libre y pleno ejercicio a toda persona que esté sujeta a su jurisdicción, sin discriminación alguna por motivos de raza, color, sexo, idioma, religión, opiniones políticas o de cualquier otra índole, origen nacional o social, posición económica, nacimiento o cualquier otra condición social". Como puede observarse, se mantienen conceptos semejantes a los adoptados hasta ese momento.

En síntesis, en esta etapa se hicieron algunos aportes fundamentales para el desarrollo del concepto etnia/raza, con una participación más amplia de las agencias del sistema internacional en el desarrollo de conceptos que se profundizaron en décadas posteriores y comienza el reconocimiento de los derechos sociales. También se hace la distinción entre la discriminación racial y la "discriminación positiva", que tiene como objetivo corregir diferencias indeseables que son frutos de la opresión o de las exclusiones pasadas. Sin embargo, persistió una visión de individuos diferentes en relación con las categorías enunciadas: raza, color, sexo, idioma, religión, condición social, lugar de nacimiento; el otro se consideraba todavía como no perteneciente. Es posible concluir que a pesar de los avances logrados en este período, se mantuvo una perspectiva etnocéntrica. En América Latina, esta situación coexistió con una sociedad civil muy incipiente dedicada a lo étnico y con un enfoque de rescate antropológico desde lo estatal que puso énfasis en la asimilación y el mestizaje como bases para la construcción de sociedades más igualitarias.

\section{Segunda etapa: 1971-1990}

En esta segunda etapa se inició el reconocimiento de la necesidad de trabajar en la eliminación de políticas segregacionistas respaldadas por el Estado. Con tal fin, en 1973 se adoptó la Convención Internacional sobre la Represión y el Castigo del Crimen de Apartheid, que tipifica el apartheid como crimen de lesa humanidad. Esta Convención califica los actos inhumanos que resultaban de las políticas y prácticas del apartheid y las políticas y prácticas análogas de segregación y discriminación racial, que se definieron en su artículo II como crímenes que violan los principios del derecho internacional y los propósitos y principios de la Carta de las Naciones Unidas. Por tanto, el apartheid adquiere también el carácter de amenaza para la paz y la seguridad internacionales (11).

En las dos décadas subsiguientes, los principios y valores acuñados en la etapa precedente se recuperaron, tanto en las instancias sectoriales como por parte de las diferentes agencias de las Naciones Unidas. Es así que en 1978, la Organización de las Naciones Unidas para la Educación la Ciencia y la Cultura (UNESCO) emitió la Declaración sobre la Raza y los Prejuicios Raciales (12). Esta Declaración, producida en el marco del Primer Decenio de Lucha contra el Racismo y la Discriminación, es categórica al establecer en su artículo 1 que "[T]odos los seres humanos pertenecen a la misma especie y tienen el mismo origen. Nacen iguales en dignidad y derechos y todos forman parte de la humanidad". En el artículo 1.2 se reconoce que "[T]odos los individuos y los grupos tienen derecho a ser diferentes, a considerarse y ser considerados como tales". Esto constituyó una evolución en cuanto a la concepción de la Declaración Universal de los Derechos Humanos, centrada en conceder derechos por encima de toda diferencia. El segundo aporte de la Declaración de la UNESCO es 
que la superación del racismo y la discriminación está asociada al logro de condiciones de justicia y paz.

A partir de esta Declaración se reconoce que todos los seres humanos pertenecen a la misma especie y tienen derecho a ser diferentes y a considerarse y ser considerados en sus diferencias. Comienza a conformarse la figura de la diversidad de las formas de vida que se traduce en el derecho a la "diferencia", aunque estas diferencias "no pueden en ningún caso servir de pretexto a los prejuicios raciales; no pueden legitimar ni en derecho ni de hecho ninguna práctica discriminatoria, ni fundar la política de apartheid que constituye la forma extrema del racismo" (artículo 2.2). Entonces, el derecho no se confiere con un criterio connivente que hace de su reconocimiento una prerrogativa etnocéntrica, sino como algo propio del género humano como un todo. Esta nueva conceptualización tiene una gran importancia en la evolución posterior del concepto etnia/raza, para la definición de la identidad cultural y la solidificación de la tolerancia. ${ }^{7}$

En el ámbito de la salud, la Conferencia Internacional sobre Atención Primaria de Salud, reunida en Alma Ata, Kazajstán, ex Unión Soviética, en 1978 (13), mostró preocupación por atender las necesidades de salud de los grupos vulnerables, cuyo acceso a la atención estaba restringido por factores "geográficos, culturales, políticos, sociales o financieros". Si bien no se hace mención al origen étnico como un determinante social de la situación de salud o del acceso a los servicios, el espíritu que impregna a la Declaración de Alma Ata (13), que surge de la Conferencia, es que al diseñar políticas y programas de salud se deben considerar las condiciones económicas y las características sociales del país y de sus comunidades. Asimismo, la Declaración de Alma Ata focalizó la atención en la priorización de lo local y favoreció la inclusión de los niveles locales, en los que se concentran los grupos étnicos/ raciales. En la misma línea, la atención primaria promueve la participación comunitaria en el diseño de políticas y reconoce que esta constituye un medio para valorizar la diversidad sociopolítica y cultural del complejo nacional.

En la estrategia planteada de atención primaria se reconoció el papel positivo de las curanderas y parteras tradicionales como agentes de influencia en las prácticas sanitarias de la comunidad. Es importante destacar que ya en 1978, la atención primaria de salud reconoció la posibilidad de complementar la capacitación de los agentes de la medicina tradicional e incorporarlos a los sistemas

\footnotetext{
Se entiende por identidad cultural la facultad que tienen los seres humanos de vivir diferente en razón de la variedad de sus culturas, del medio ambiente y de su historia. De esta facultad se desprenden dos derechos: a vivir diferente y a preservar la identidad.
}

nacionales de salud. En consonancia con la Resolución del Comité Regional para África de la Organización Mundial de la Salud, aprobada en 2000, en ese continente se adoptó en 2001 la medicina tradicional como una estrategia prioritaria para extender la cobertura de los servicios y las autoridades de salud convinieron en establecer una década para su desarrollo (14).

En esta etapa se produjo en América Latina un profundo replanteo de las democracias, como consecuencia del regreso progresivo al constitucionalismo en la mayoría de los países. La nueva democracia comenzó con la reconstrucción del Estado mediante la descentralización administrativa. Esta estrategia revalorizó lo local y evidenció la existencia de grupos a nivel comunitario - como los grupos étnicos/raciales- que mantenían vivas sus culturas y tradiciones. A esto se agregó una revisión de la relación Estado-individuo, que se manifestó en la necesidad de hacer efectivo un conjunto de derechos que habían estado suspendidos durante los regímenes de facto.

Los procesos de transición a la democracia en América Latina dieron lugar a una revitalización de la sociedad civil y generaron nuevos foros de discusión y reivindicación de los derechos comprendidos en el concepto de ciudadanía. Como parte de este proceso, la sociedad civil se diversificó e incorporó organizaciones que representaban temas y segmentos de la población que no habían estado organizados anteriormente. Las organizaciones de mujeres y las que representaban a minorías étnicas/raciales, junto con las entidades de nivel local, se organizaron para reivindicar una mayor participación y medidas para eliminar la discriminación de género y étnica/racial. Surgió entonces, como un nuevo desafío de la democracia, la necesidad de responder al reclamo de inclusión social y política de grupos que hasta entonces habían permanecido marginados.

En esta etapa, América Latina fue también escenario de una actividad creciente del movimiento por los derechos de las mujeres y se obtuvieron importantes logros en términos de participación política y de acceso al mercado de trabajo. Por otra parte, favorecidos por los procesos de reconstrucción democrática, los movimientos que representaban a las minorías étnicas avanzaron en la elaboración y "complejización" de sus plataformas de reivindicaciones. Nuevos temas - como el reconocimiento de ser Estados pluriétnicos, pluriculturales y multilingües - acompañaron las demandas sobre la construcción de las identidades y derechos de los pueblos indígenas. En este período, también el movimiento indígena ganó solidez en su estructura, superó segmentaciones, articuló sus redes y fortaleció su capacidad de diálogo con el Estado, lo que le permitió ejercer funciones de abogacía. 
El Convenio 169 sobre Pueblos Indígenas y Tribales en Países Independientes (15), adoptado por la Organización Mundial del Trabajo en 1989, fue uno de los instrumentos clave para fortalecer el proceso de estructuración del movimiento social que representaba a los pueblos indígenas. Desde la etapa de su discusión, este Convenio se caracterizó por la participación social. La participación de los líderes y representantes de las comunidades de base fue decisiva en la definición misma de los pueblos indígenas y tribales, lo que contribuyó a la construcción de la propia identidad de los países de la Región. Para América Latina, este Convenio tiene la particularidad de haberse discutido y adoptado en los años previos a la conmemoración de los 500 años de la llegada de los europeos a las Américas.

Este Convenio reconoció la necesidad de revisar la normativa internacional con vistas a eliminar la orientación hacia la asimilación, propia de la etapa anterior. Asimismo, consideró como sus beneficiarios a dos grupos étnicos: los pueblos tribales y los pueblos indígenas. ${ }^{8}$ Los pueblos tribales se distinguen de otros sectores de la colectividad nacional "por sus condiciones sociales, culturales y económicas" y se encuentran "regidos total o parcialmente por sus propias costumbres o tradiciones o por una legislación especial. Se consideran pueblos indígenas a los descendientes de las poblaciones que habitaban el país antes de la época de la conquista o la colonización o del establecimiento de las actuales fronteras estatales y "que, cualquiera que sea su situación jurídica, conserv[e]n todas sus propias instituciones sociales, económicas, culturales y políticas, o parte de ellas" (Artículo 1.a y 1.b). Esta definición también establece que un componente central de la identidad es la preservación de las culturas propias y la conservación de sus instituciones sociales, económicas y culturales.

La aprobación del Convenio 169 inspiró la formulación de legislaciones basadas en el concepto operativo de poblaciones indígenas y tribales. Si bien este concepto fue aceptado a nivel global y se aplicó a todas las culturas que antecedían al proceso de colonización, en América Latina generó dos importantes fenómenos. El primero de ellos fue la identificación más adecuada de los pueblos indígenas y tribales en su especificidad y con sus características e identidades propias; el otro, fue la "invisibilización" de un importante contingente humano cuyos ancestros llegaron a la Región en condiciones forzadas durante la época colonial, como los descendientes de africanos.

La imposibilidad de encuadrar a los afrodescendientes en la categorización operativa utilizada

\footnotetext{
8 Antes de la emisión del Convenio 169 se utilizaba una terminología diversa para referirse a los pueblos precolombinos: aborígenes, nativos, indios e indígenas, entre otros.
}

por el Convenio 169 - porque al ser trasladados a la Región perdieron sus lenguas de origen y la mayoría de sus instituciones no sobrevivieron al proceso de la diáspora- ocasionó su exclusión de las políticas y programas con enfoque étnico generados durante el decenio de 1990. Más aun, por las condiciones de su inserción política, económica y social, este grupo fue susceptible a las políticas de asimilación, con la consiguiente debilitación de su identidad. En el ámbito académico de algunos países de la región, como Brasil, Colombia y Ecuador, se comenzaron a cuestionar los mitos de la "democracia racial" y el mestizaje como vía para crear la identidad (16) y lograr la integración.

En esta segunda etapa se revitalizó el tema de los derechos humanos en las agencias del Sistema de las Naciones Unidas, las que apoyaron la ampliación de este tema al ámbito sectorial y social. La lucha contra el racismo y la discriminación asumió nuevas formas en la medida en que en la Región se formulaban reivindicaciones relacionadas con el multiculturalismo de las sociedades y la necesidad de otorgar a los Estados la capacidad de representar a sociedades multiétnicas y multilingües. En este proceso se consolidaron liderazgos indígenas que ya se perfilaban desde mediados de la década de 1970, lo que dio lugar a un movimiento de reivindicación de carácter étnico. La gran mayoría de los pueblos precolombinos se asumieron a sí mismos como pueblos indígenas y se reconocieron como grupos étnicos, lo que dio a la identidad cultural un valor de elemento constitutivo. Al importante contingente de latinoamericanos descendientes de africanos - a los que en algunos documentos se refieren como afrolatinos- "invisibilizados" se sumaron otros grupos de menor peso demográfico, como algunos grupos de inmigrantes y pueblos rom, que conservaban un marcado acervo cultural y lingüístico.

En esta etapa, algunos países fueron pioneros en estudiar las condiciones de vida de los grupos étnicos y en identificar los elementos centrales de la identidad. Estos estudios permitieron profundizar en la evolución del concepto etnia/raza. Los pueblos indígenas, apoyados en el proceso generado por la discusión del Convenio 169, desempeñaron un papel muy activo y ganaron presencia a nivel del Estado. Está claro que uno de sus mayores logros fue el reconocimiento de la identidad como elemento constitutivo del individuo y vivir la identidad propia se elevó a nivel de derecho.

\section{Tercera etapa: 1991-2000}

En esta etapa, la Conferencia Mundial de Derechos Humanos refrendó en la Declaración y Programa de Acción de Viena de 1993 la importancia 
de la democracia y del desarrollo para la vigencia de los derechos (17). Con esta Declaración, el rechazo a la discriminación salió del ámbito individual y se insertó en la agenda estatal al analizar las modalidades para albergar la diversidad. Asimismo, se asociaron los conceptos de no discriminación y de inclusión social.

Esta Declaración fue novedosa por diversificar los fenómenos que se querían superar, como la xenofobia y la intolerancia. La Declaración también amplió el alcance de los grupos vulnerables al incorporar a las mujeres, las minorías lingüísticas, los niños y niñas, los discapacitados, los pueblos indígenas y los trabajadores migrantes. Más aun, en su inciso 24 se establecía la obligación de los Estados de adoptar y mantener "medidas adecuadas en el plano nacional, en particular en materia de educación, salud y apoyo social, para promover y proteger los derechos de los sectores vulnerables de la población y asegurar la participación de las personas pertenecientes a esos sectores en la búsqueda de una solución a sus problemas".

La Conferencia Mundial de Derechos Humanos terminó con la recomendación a la Asamblea General, a la Comisión de Derechos Humanos y a otros órganos y organismos del Sistema de las Naciones Unidas, de proclamar el Decenio de las Naciones Unidas para los Derechos Humanos. La Conferencia recomendó también que la Comisión de Derechos Humanos examinara cada año los progresos logrados en la aplicación de las recomendaciones de la Declaración y Programa de Acción de Viena. Con esta solicitud se estimuló la adopción en los Estados de las medidas necesarias para lograr los objetivos mencionados.

En este período, el Comité de Derechos Económicos, Sociales y Culturales del Consejo Económico y Social de las Naciones Unidas hizo una revisión sobre la aplicación del artículo 13 del Pacto Internacional de Derechos Económicos, Sociales y Culturales, de 1966, relativo al derecho de toda persona a la educación. Con relación al párrafo 2 en particular, el Comité estableció en su observación No. 13 que los Estados tienen la obligación de "respetar, proteger y llevar a efecto cada una de las características fundamentales (disponibilidad, accesibilidad, aceptabilidad y adaptabilidad) del derecho a la educación". La aceptabilidad de la educación implica la adopción de "medidas positivas para que la educación sea culturalmente aceptable para las minorías y las poblaciones indígenas" (18).

La Conferencia de las Naciones Unidas sobre el Medio Ambiente y el Desarrollo, celebrada en Río de Janeiro, Brasil, en 1992, asoció el tema de las poblaciones indígenas al mantenimiento de la estabilidad ambiental y a la interdependencia creciente entre los países. La Agenda 21, que surgió de esa reunión cumbre, puso énfasis en el uso racional de los recursos y su conservación con miras al desarrollo sostenible. Apareció entonces el énfasis en que "las poblaciones indígenas y sus comunidades, así como otras comunidades locales, desempeñan un papel fundamental en la ordenación del medio ambiente y en el desarrollo, debido a sus conocimientos y prácticas tradicionales". Como consecuencia, se estableció que los Estados deben reconocer y apoyar debidamente la identidad, cultura e intereses de esas poblaciones y posibilitar su participación efectiva en el logro del desarrollo sostenible.

Esto significó dar prioridad a la participación de las poblaciones indígenas en la planificación del desarrollo sostenible y reconocer el vínculo entre ellas y los territorios ricos en recursos naturales en los que habitan. Al mismo tiempo, se potenció el conocimiento ancestral de esas poblaciones sobre la utilización de dichos recursos, lo que significaba reconocer la importancia de la diversidad desde un enfoque que trasciende lo cultural para insertarse en lo científico. Surgió así una nueva estrategia para el empoderamiento de esas poblaciones mediante el cumplimiento de los convenios derivados de la Agenda 21 y la obligación de legislar a nivel nacional sobre el derecho de propiedad intelectual y cultural indígena y la protección del ambiente. Si bien la Agenda 21 promovió el apoyo a la medicina tradicional, la referencia a las poblaciones indígenas dejó fuera a otros grupos étnicos de población también numerosa, como los afrolatinos.

La Declaración de la IV Conferencia de las Naciones Unidas sobre la Mujer, realizada en 1995 en Beijing, China (19), hizo una sola mención al tema etnia/raza al instar a los Estados a "[I]ntensificar los esfuerzos para asegurar el disfrute, en condiciones de igualdad, de todos los derechos humanos y libertades fundamentales a todas las mujeres y las niñas que se enfrentan con múltiples barreras para su empoderamiento y su avance por factores tales como la raza, la edad, el idioma, el origen étnico, la cultura, la religión o la discapacidad o porque son población indígena". El gran aporte de esta Declaración radica en hacer evidente que cuando existen factores de discriminación que se superponen, como los de género y los de origen étnico/ racial, la vulnerabilidad de la población se intensifica. El origen étnico/racial aparece como un determinante social de las condiciones de vida y salud.

En 1994 comenzó el Decenio Internacional de las Poblaciones Indígenas del Mundo, convocado por las Naciones Unidas (20), y se estableció como meta fortalecer la cooperación internacional para la solución de los problemas que enfrentan los indígenas en aspectos tales como los derechos humanos, la educación, el medio ambiente, el desarrollo y la salud. Se invitó a los gobiernos a establecer comités 
nacionales y otras estructuras de carácter permanente en los que participaran representantes de las poblaciones indígenas, a fin de planificar las actividades para el decenio.

El tema étnico apareció con mucha fuerza en las agendas de los países desarrollados, en particular de Europa, debido a crueles enfrentamientos entre diferentes grupos étnicos que produjeron pérdidas de vidas, oportunidades truncadas para las generaciones jóvenes y un considerable contingente de refugiados en muchos países europeos. Entre 1992 y 1995, tres grupos étnicos - los serbios, los croatas y los musulmanes - se enfrentaron cruelmente en la República de Bosnia y Herzegovina. En Ruanda, las milicias de los hutus asesinaron a más de 800000 tutsis. Alrededor de $10 \%$ de la población de Ruanda fue víctima de la violencia étnica en solo tres meses y, según el Fondo de las Naciones Unidas para la Infancia (UNICEF), 95000 niños perdieron a sus padres en el conflicto. Este tipo de enfrentamientos llevó a los gobiernos de los países desarrollados y a las organizaciones internacionales a incorporar los temas de la discriminación, la xenofobia y el racismo en sus agendas. En el Sistema de las Naciones Unidas, esta preocupación se expresó en la convocatoria a la Tercera Conferencia Mundial contra el Racismo, la Discriminación Racial, la Xenofobia y las Forma Conexas de Intolerancia, que se celebraría en 2001.

En la Región de las Américas, esta tercera etapa está marcada por la conmemoración del quinto centenario del arribo de los europeos a las Américas, lo que condujo a la revalorización de lo pluricultural como característica de las sociedades actuales. Hay una inflexión importante en el espacio que se le otorgaba a lo étnico, pues dejó de ser solamente una categoría de la historia precolombina para convertirse en un componente social y demográfico de la actualidad.

La revitalización de la democracia en la Región se acompañó de la realización sistemática de las Cumbres de Jefes de Estado y de Gobierno de América Latina, España y Portugal, iniciadas en 1991 en Guadalajara, México. Estas reuniones constituyen un espacio de discusión de temas de desarrollo político y social, basado en la revalorización de los vínculos históricos que unen a España, Portugal y América Latina. Coincidiendo con los preparativos para la celebración de los 500 años de interacción entre Europa y las Américas, la Cumbre de Guadalajara buscó proyectar la fuerza de la comunidad iberoamericana en el tercer milenio.

El anuncio de la adopción por parte de la comunidad internacional de 1993 como Año Internacional de los Pueblos Indígenas también contribuyó a que en la Declaración de la Cumbre se reconociera el aporte de los pueblos indígenas y "la inmensa contribución de los pueblos indígenas al desarrollo y pluralidad de nuestras sociedades y [se reiterara el] compromiso por su bienestar económico y social, así como la obligación de respetar sus derechos y su identidad cultural" (21). Como consecuencia de esto, los jefes de Estado y de gobierno iberoamericanos propusieron crear un fondo iberoamericano para el desarrollo de los pueblos indígenas, con el apoyo de los organismos internacionales. El objetivo de este fondo es contribuir a resolver favorablemente "los problemas acuciantes de los pueblos originarios, al margen de cualquier sentido de reservas indígenas o compensaciones paternalistas" (21).

En el curso de la Segunda Cumbre Iberoamericana, celebrada en 1992 en Madrid, España, se hicieron operativas las conclusiones emanadas de la Cumbre de Guadalajara de 1991 y se firmó el Convenio Constitutivo del Fondo para el Desarrollo de los Pueblos Indígenas de América Latina y el Caribe. La Tercera Cumbre, celebrada en 1993 en la ciudad de Bahía, Brasil, informó sobre los avances en la organización de este Fondo. ${ }^{9}$ El Convenio estableció dos órganos de dirección: la Asamblea General y el Consejo Directivo. En ambos órganos se previó la participación de los gobiernos y de delegados de los pueblos indígenas, lo que favorecía la creación de un mecanismo de canalización directa de las demandas de estos pueblos. La Asamblea General debía aprobar los proyectos que el Fondo desarrollara, lo que garantizaba el respaldo de los delegados de los pueblos indígenas en la gestión técnica de la institución.

En los países de América Latina, en particular, se comenzó a repensar el tema de la construcción de la nación en el marco de las transiciones democráticas, y el cuestionamiento de la naturaleza de sus sociedades volvió con fuerza a entrar en la agenda social. Se analizaron los mecanismos de integración social utilizados en el pasado y sus resultados. La estrategia de asimilación que minimizaba las diferencias entre los grupos se veía ahora superada por otra que llevaba a valorizarlas y se sustituyó el concepto de homogenización y el etnoculturalismo por el de sociedades plurales multiculturales. La tolerancia a la diversidad comenzó a ser un nuevo valor propio de este paradigma que llevó a la necesidad de crear una nueva concepción del sujeto de dere-

\footnotetext{
9 El Comité Interino del Fondo comenzó a funcionar en 1994 con Bolivia, Chile, México y Nicaragua, un representante del Gobierno de España y un representante del Gobierno de Portugal. Para esa fecha habían firmado el Convenio Argentina, Bolivia, Brasil, Chile, Colombia, Costa Rica, Cuba, Ecuador, España, Honduras, México, Nicaragua, Panamá, Paraguay, Portugal, República Dominicana y Uruguay; Perú y Venezuela habían manifestado su interés en ser miembros. Los organismos internacionales que apoyaron el proyecto fueron el Banco Interamericano de Desarrollo, el Instituto Indigenista Interamericano, la Organización Internacional del Trabajo, la Organización de las Naciones Unidas para la Educación, la Ciencia y la Cultura, y el Programa de las Naciones Unidas para el Desarrollo.
} 
cho, que permitiera reconocer al diferente como un igual pleno (22). A nivel más global, esta etapa coincidió con la posmodernidad, caracterizada por repensar la identidad desde la diferencia. "La identidad se ve como algo construido mediante complejos proceso de relacionalidad y representación" (16).

Como síntesis de este período en la Región de las Américas se puede anotar que el tema de los derechos de los pueblos indígenas comenzó a incorporarse a todas las manifestaciones políticas, se reconocieron sus saberes, se crearon instancias de distintas naturalezas a nivel nacional (unidades, programas o institutos), se estableció un marco temporal para mantener activos los esfuerzos y se aprobó el Decenio de los Pueblos Indígenas. Se aceptó que para poder alcanzar logros tangibles, se necesitaban compromisos sólidos que no se interrumpieran con los cambios de gobierno. También se inició el análisis de los factores discriminatorios cuando son acumulativos, como el género, la etnia/raza y la pobreza, como demuestran muchos estudios.

No obstante, se debe señalar que el interés estuvo fundamentalmente centrado en los pueblos indígenas y se prestó mucho menos atención a otros grupos, como los migrantes, los pueblos rom y los afrolatinos. En el mejor de los casos, esas poblaciones entraban en una categoría más difusa como "otros", tal como se observó durante esta etapa en algunas de las boletas de recolección de información en censos y encuesta de hogares. Por lo tanto, persistió la idea de que los pueblos indígenas eran los únicos que contaban con una riqueza cultural que les permitía definirse como "grupo especial", mientras el resto se mezclaba anónimo en el conjunto de la población.

\section{Cuarta etapa: 2001 hasta el presente}

Esta etapa está marcada por el proceso de organización y la realización de la Tercera Conferencia Mundial contra el Racismo, la Discriminación Racial, la Xenofobia y las Formas Conexas de Intolerancia, convocada por las Naciones Unidas y celebrada del 31 de agosto al 7 de septiembre de 2001 en Durban, Sudáfrica. El aporte más novedoso de esta Conferencia fue la incorporación expresa de los descendientes de africanos, los migrantes y los desplazados como poblaciones beneficiarias de las políticas antidiscriminatorias (2). La Conferencia reflejó la coyuntura sociopolítica imperante, en la que las migraciones económicas y los desplazamientos por los conflictos étnicos en Serbia y en Bosnia y Herzegovina impactaron a Europa.

América Latina desempeñó un papel muy dinámico en el proceso de preparación de esta Confe- rencia, especialmente por la coordinación de los países en el seguimiento de los acuerdos preexistentes en materia de derechos humanos, en particular de los acuerdos adoptados en la reunión regional preparatoria, realizada en diciembre de 2000 en Santiago, Chile (23).

Otro aspecto en el que se destacó la Región fue por el surgimiento de un nuevo actor social a nivel regional: los afrodescendientes, ya que independientemente del país en que habitaran, compartían ancestros provenientes de África con el consiguiente acervo cultural común. Esta característica permitió articular una red de organizaciones de base integradas por descendientes de africanos o dedicadas a temas prioritarios de sus comunidades. Por último, se logró estrechar la relación entre personas con ancestros africanos comunes que vivían en América Latina, el Caribe de habla inglesa y los Estados Unidos de América. Esta relación, a partir de una base cultural común, solo pudo lograrse mediante el reconocimiento de tener un mismo origen y circunstancias de vida similares. El proceso de abogacía promovido por el segmento de la sociedad civil compuesto por afrodescendientes logró incidir en la Declaración de Durban y llevó a que los delegados repudiaran no solo la esclavitud, sino también la trata transatlántica de esclavos.

Además de definir todos los grupos víctimas del racismo, la Conferencia de Durban identificó las diversas formas de discriminación: el racismo, la discriminación racial, la xenofobia y otras formas conexas de intolerancia. Por último, mediante su Plan de Acción, ahondó en recomendaciones que deben contribuir a que los Estados superen esta crítica situación de cara al nuevo milenio, con énfasis en aspectos ambientales, educacionales, laborales $y$, muy particularmente, en la salud.

La Conferencia de Durban y los avances organizativos de la sociedad civil permitieron consolidar políticas y lograr que a partir de 2001 los compromisos de algunos gobiernos se visibilizaran, y los conceptos de grupo étnico y de diversidad cultural estuvieran presentes con mayor frecuencia en las declaraciones de los jefes de Estado. Las Naciones Unidas adoptaron progresivamente este nuevo paradigma en el tratamiento de los grupos étnicos y lo trasladó a los foros de gravitación política. Por ejemplo, en las palabras dirigidas por el ex Secretario General de la Organización de las Naciones Unidas Kofi Annan a los Jefes de Estado reunidos en la XIII Cumbre Iberoamericana de Jefes de Estado y de Gobierno de América Latina, España y Portugal, realizada en noviembre de 2003 en Santa Cruz de la Sierra, Bolivia, enfatizó que ". . . una estrategia de desarrollo digna de este nombre no puede soslayar las desigualdades patentes ente los distintos grupos sociales, lo cual es aun más cierto cuando diferencias 
socioeconómicas coinciden con las divisiones étnicas. Habría que prestar especial atención a las necesidades de quienes comparten la amarga experiencia de la marginación, ya se trate de minorías o mayorías, de ascendencia africana u origen indígena" (24).

En este período se celebraron la IV Cumbre de las Américas en noviembre de 2005 en Mar del Plata, Argentina, y la XVI Cumbre Iberoamericana de Jefes de Estado y de Gobierno de América Latina, España y Portugal, en Montevideo, Uruguay, un año después. En la primera de estas Cumbres se reafirmó la urgencia de prestar atención especial a las necesidades basadas en el género, así como a las necesidades específicas de los pueblos indígenas y afrodescendientes, entre otros grupos en situación de vulnerabilidad. Asimismo, los participantes en la Cumbre reafirmaron "su compromiso de respetar los derechos de los pueblos indígenas" y de "concluir exitosamente las negociaciones de la Declaración Americana sobre los Derechos de los Pueblos Indígenas". Se comprometieron también a "respetar los derechos de los afrodescendientes y asegurar su pleno acceso a las oportunidades de educación en todos los niveles y al trabajo decente que les ayudará a superar la pobreza y la exclusión social y contribuirá a que se aumente su participación en todos los sectores de la sociedad" (25).

La Cumbre Iberoamericana de Jefes de Estado y de Gobierno de América Latina, España y Portugal, celebrada en Montevideo en 2006, adoptó la Carta Cultural Iberoamericana, que afirma que "las culturas tradicionales, indígenas, de afrodescendientes y de poblaciones migrantes en sus múltiples manifestaciones son parte relevante de la cultura y de la diversidad cultural iberoamericana, y constituyen un patrimonio fundamental para la humanidad". En las recomendaciones de esta Cumbre se instó a la elaboración de indicadores específicos en relación con los pueblos indígenas y afrodescendientes, que sirvan de herramienta útil para avanzar en la lucha contra la exclusión y la pobreza en que se encuentran estos grupos en muchos países de la Región (26).

En esta última etapa, las Naciones Unidas adoptaron el 13 de septiembre de 2007 la Declaración de los Pueblos Indígenas (27), que recupera el espíritu del Convenio 169 de 1989. La Declaración reconoce a los integrantes de los pueblos indígenas los mismos derechos de que goza el resto de los miembros de la sociedad. Establece, además, derechos específicos, entre ellos el derecho a sus prácticas tradicionales, al respeto de sus conocimientos y culturas, a la repatriación de sus objetos de culto, a la revitalización de sus sistemas de escritura y a la creación de establecimientos educativos en su propia cultura e idioma. Este reconocimiento tiene im- plicaciones en la formulación de políticas y en la construcción de Estados multiétnicos, multiculturales y multilingües. Asimismo, reconoce el derecho a la libre determinación y autogobierno de los pueblos indígenas y a la propiedad y el usufructo de las tierras que históricamente les pertenecieron, con lo cual contribuye a reafirmar la responsabilidad del Estado de crear canales para su participación social y política.

\section{CONCLUSIONES}

Este estudio muestra la evolución positiva experimentada por el concepto etnia/raza en los principales documentos y convenios internacionales. El tratamiento del tema está relacionado con la búsqueda de la igualdad y la superación de los resultados de la opresión a la que habían estado sometidos los grupos étnicos/raciales. Un hito importante en esta evolución es el reconocimiento de que todos los seres humanos pertenecen a la misma especie y tienen el mismo origen y que la humanidad es una sola.

Si bien se reconoció que la humanidad es una unidad indivisible, solo tiempo después se aceptó la existencia de identidades diversas que, por primera vez, generaron el derecho a ser vividas en sus diferencias. Se aceptó también que las diferencias entre los seres humanos son producto de formas de vida, creencias y cosmovisiones que dan lugar a comportamientos diversos y se manifiestan en maneras de vestir, lenguajes, rituales, terapias, alimentación y formas de organización social diferentes. Como resultado de esta evolución, en la Región de las Américas se reconoce dentro del conglomerado de grupos étnicos/raciales no solo a los pueblos indígenas, sino a otros grupos como los afrodescendientes, los migrantes, los pueblos rom, los desplazados y los refugiados, ya que todos ellos tienen acervos culturales propios.

La evolución del concepto etnia/raza influye en la formulación de políticas públicas de diversas maneras. La identificación de las diferencias permite precisar las necesidades concretas de los beneficiarios. En lugar de pensar en un beneficiario abstracto, con las limitaciones que ello ocasiona, se deben tomar en cuenta los elementos que conforman la identidad para diseñar programas más sensibles a sus particularidades. Las políticas, entonces, no se restringen a observar igualdad de trato frente a las diferencias de fenotipo o al color de la piel — que homogeneizaba la oferta de servicios-, sino que deben buscar facilitar el acceso en consideración a los requisitos derivados de la diversidad propia de sus culturas. 
La sensibilidad del campo social por el respeto a la diversidad llevó a una identificación de la discriminación institucional, distinta de la discriminación de la esfera interpersonal; se debe distinguir la discriminación que ejercen los individuos, incluso cuando prestan servicios, de la omisión de las instituciones en adaptar la oferta de sus servicios a las necesidades particulares de los beneficiarios. Como prueba de esto, en la última generación de políticas se incorporan acciones afirmativas, como una forma de reducir las inequidades persistentes derivadas de exclusiones propias de épocas anteriores. La equidad, entendida como la superación de las diferencias injustas y evitables, ha constituido un elemento muy positivo como trazador de las políticas públicas dirigidas a combatir la discriminación, ya que esta es injusta y evitable por naturaleza.

En la última etapa, los acuerdos de los jefes de Estado de la Región han tenido un efecto positivo en el proceso de revisión de las responsabilidades del Estado en el combate contra la discriminación. Esto ha llevado a la creación de instituciones con mandatos más amplios, cuya función es velar por la incorporación de la perspectiva étnica/racial en todos los niveles del Estado y promover programas específicos de desarrollo, como la Secretaría para la Promoción de las Políticas de Equidad Racial de Brasil y el Fondo para el Desarrollo Indígena, entre otras. Como complemento se ha fortalecido la participación social en el diagnóstico de la situación y en el diseño y formulación de políticas y programas, con el consiguiente empoderamiento de los grupos étnicos/raciales.

En última instancia, el resultado del proceso de evolución positiva del concepto etnia/raza en las últimas cinco décadas, se ha traducido en una mayor valorización del reconocimiento de las diferencias, lo que define a las sociedades plurales y multiétnicas y trasciende el beneficio que reciben los grupos en sí mismos. Este concepto se consti- tuye así en un factor sustancial para el avance de las sociedades democráticas y sienta bases más sólidas para el desarrollo.

\section{SYNOPSIS}

\section{The evolution of the ethnicity/race concept and its impact on framing policies that promote equity}

Acknowledging the differences between individuals based on their unique identity is a basic requirement for achieving equity. A review of international human rights efforts and the recommendations and declarations of global conferences and regional summits as they redirect policy to battle discrimination shows a positive evolution in the concept of ethnicity/race. This is evident in the transition from using "invisible" differences as an equalizing measure to respecting lifestyle diversity and acknowledging that individuals have a right to be valued for their differences. This evolution in the ethnicity/race concept has been pivotal to building multiethnic, multicultural, and multilingual nations in which minority groups are involved in framing equitable health policies and programs. This study covers the time period from 1948 to the present day, identifying four stages in the concept's evolution that coincide with milestones in the political and social relationship between government institutions and ethnic minority groups. The results of these five decades of positive progress is a heightened appreciation for differences, which underlies multiethnic societies and surpasses any one of the tangible benefits received by minority groups. The progress of democratic societies depends heavily on this concept, one that ensure a stronger foundation for future development.

Key words: human rights, prejudice, ethnic group and health, equity in health, literature review, Americas.

\section{REFERENCIAS}

1. Naciones Unidas. Declaración Universal de los Derechos Humanos. Resolución de la Asamblea General 217 A (iii); 10 de diciembre de 1948. Nueva York: Naciones Unidas; 1948. Hallado en http:// www.un.org/spanish/aboutun/hrights. $\mathrm{htm}$. Acceso el 14 de noviembre de 2007.

2. Naciones Unidas. Informe de la Conferencia Mundial contra el Racismo, la Discriminación Racial, la Xenofobia y las
Formas Conexas de Intolerancia; 31 de agosto a 8 de septiembre de 2001; Durban, Sudáfrica. Nueva York: Naciones Unidas; 2002. (Documento A/CONF.189/ 12). Hallado en http://www.unhchr. ch/huridocda/huridoca.nsf/(Symbol)/ A.Conf.189.12.Sp?Opendocument. Acceso el 14 de noviembre de 2007.

3. Gannett, L. The biological reification of race. Br J Philos Scie. 2004;55(2): 323-45.
4. Long JC, Kittles RA. Human genetic diversity and the nonexistence of biological race. Hum Biol. 2003;75(4):449-71.

5. Mayr E. The biology of race and the concept of equality. Daedalus. 2002;131(1): 89-94.

6. Naciones Unidas. Nota del Secretario General por la que se transmite el informe de la Reunión de Consulta sobre la Conferencia Mundial contra el Ra- 
cismo, la Discriminación Racial, la Xenofobia y las Formas Conexas de Intolerancia. Nueva York: Naciones Unidas; 2000. (Documento A/CONF.189/PC.1/ 10. 8).

7. Koonings K, Silva P. Construcciones étnicas y dinámica sociocultural en América Latina. Quito: Ediciones Abya Yala; 1999.

8. Naciones Unidas. Convención Internacional sobre la Eliminación de Todas las Formas de Discriminación Racial. Nueva York; 1965. Hallado en http:// www.unhchr.ch/spanish/html/menu3 /b/d_icerd_sp.htm. Acceso el 14 de noviembre de 2007.

9. Naciones Unidas. Pacto Internacional de Derechos Económicos, Sociales y Culturales. Nueva York: Naciones Unidas; 1966. Hallado en http://www.unhchr. $\mathrm{ch} / \mathrm{spanish} / \mathrm{html} / \mathrm{menu} 3 / \mathrm{b} /$ a_cescr sp.htm. Acceso el 14 de noviembre de 2007.

10. Organización de Estados Americanos. Convención Americana sobre Derechos Humanos (Pacto de San José de Costa Rica). Washington, D.C.: OEA; 1969. Hallado en http://www.oas.org/juridico/ spanish/tratados/b-32.html. Acceso el 14 de noviembre de 2007.

11. Naciones Unidas. Convención Internacional sobre la Represión y el Castigo del Crimen de Apartheid. Nueva York: 1973. Hallado en http://www.unhchr. ch/spanish/html/menu3/b/11_sp.htm. Acceso el 14 de noviembre de 2007.

12. Organización de las Naciones Unidas para la Educación, la Ciencia y la Cultura. Declaración sobre la Raza y los Prejuicios Raciales. París: UNESCO; 1978. Hallado en http://www.unhchr.ch/ spanish/html/menu3/b/d_prejud_sp. htm. Acceso el 14 de noviembre de 2007.

13. Organización Mundial de la Salud. Atención Primaria de Salud. Informe de la Conferencia Internacional sobre Atención Primaria de Salud; 6-2 de septiembre de 1978; Alma-Ata, Kazajstán, ex Unión Soviética. Ginebra: OMS; 1979.
14. Chatora R. An overview of the traditional medicine situation in the African Region. WHO Afr Health Mon. 2003; 4(1):4-7.

15. Organización Internacional del Trabajo. Convenio sobre Pueblos Indígenas y Tribales en Países Independientes. Ginebra: OIT; 1989. (Documento OIT No. 169). Hallado en http://www.unhchr. $\mathrm{ch} /$ spanish/html/menu3/b/62_sp.htm. Acceso el 14 de noviembre de 2007.

16. Wade P. Raza y etnicidad en América Latina. Quito: Ediciones Abya Yala; 2000.

17. Naciones Unidas, Asamblea General. Declaración y Programa de Acción de Viena. Conferencia Mundial de Derechos Humanos. Viena: Naciones Unidas; 1993. (Documento A/CONF.157/23).

18. Naciones Unidas, Consejo Económico y Social, Comité de Derechos Económicos, Sociales y Culturales. El derecho a la educación (Artículo 13). Aplicación del Pacto Internacional de Derechos Económicos, Sociales y Culturales. 21. $\mathrm{Pe}$ ríodo de Sesiones. Ginebra: Oficina del Alto Comisionado de las Naciones Unidas para los Derechos Humanos; 1999. (Documento E/C.12/1999/10).

19. Naciones Unidas. Informe sobre la Cuarta Conferencia Mundial sobre la Mujer. Nueva York: Naciones Unidas; 1996. (Documento A/CONF.177/20).

20. Naciones Unidas, Asamblea General. Resolución de la Asamblea General 48/163 sobre el Decenio Internacional de las Poblaciones Indígenas del Mundo. Nueva York: Naciones Unidas; 1994. (Documento A/RES/48/163).

21. Cumbre Iberoamericana. Declaración de Guadalajara. I Cumbre Iberoamericana de Jefes de Estado y de Gobierno de América Latina, España y Portugal; 19 de julio de 1991; Guadalajara, México. Hallado en http:/ / www.integracionsur. com/americalatina/CumbreALatina EuropaDclGuadalajara.htm. Acceso el 14 de noviembre de 2007.

22. Touraine A. Pourrant-nous vivre ensemble? Egaux et différents. Paris: Fayard; 1998.
23. Naciones Unidas. Conferencia Mundial Contra el Racismo, la Discriminación Racial, la Xenofobia y las Formas Conexas de Intolerancia. Informe del Seminario regional de expertos para América Latina y el Caribe sobre medidas económicas, sociales y jurídicas para luchar contra el racismo, con referencia especial a los grupos vulnerables; $25-27$ de octubre de 2000; Santiago, Chile. Nueva York: Naciones Unidas; 2001. (Documento A/CONF.189/PC.2/5). Hallado en http://www.unhchr.ch/huridocda/ huridoca.nsf/(Symbol)/A.CONF.189. PC.2.5.Sp?Opendocument. Acceso el 14 de noviembre de 2007.

24. Annan K. Discurso ante la XIII Cumbre Iberoamericana de Jefes de Estado y de Gobierno de América Latina, España y Portugal; 14 de noviembre de 2003; Santa Cruz de la Sierra, Bolivia. Nueva York: Naciones Unidas; 2003.

25. Declaración de Mar del Plata. Crear trabajo para enfrentar la pobreza y fortalecer la gobernabilidad democrática. Cuarta Cumbre de las Américas; 5 de noviembre de 2005; Mar del Plata, Argentina. Buenos Aires; 2005. Hallado en http://www.iin.oea.org/ DECLARACIONES/declaracion_IV Cumbre_de_las_Americas.htm. Acceso el 29 de septiembre de 2007.

26. Cumbre Iberoamericana. Declaración de Montevideo. XVI Cumbre Iberoamericana de Jefes de Estado y de Gobierno de América Latina, España y Portugal; 5 de noviembre de 2006; Montevideo, Uruguay. Hallado en http://www. cinterfor.org.uy/public/spanish/region/ ampro/cinterfor/temas/employer / eventos/xvi_dec.pdf. Acceso el 14 de noviembre de 2007.

27. Naciones Unidas. Declaración de las Naciones Unidas sobre los Derechos de los Pueblos Indígenas. Nueva York: Naciones Unidas; 2006. (Documento A/RES/61/295). Hallado en http:// www. servindi.org/pdf/ONU_ Dec PI.pdf. Acceso el 14 de noviembre de 2007. 